\title{
Efficacy of synthetic glucocorticoids in COVID-19 endothelites
}

\author{
Francesco Ferrara $^{1}$ (D) Antonio Vitiello ${ }^{2}$ (D) \\ Received: 9 December 2020 / Accepted: 6 January 2021 / Published online: 14 January 2021 \\ (C) The Author(s), under exclusive licence to Springer-Verlag GmbH, DE part of Springer Nature 2021
}

\begin{abstract}
Since March 2020, the world has been fighting a global pandemic caused by a new coronavirus SARS-CoV-2 (COVID-19). SARS-CoV-2 is responsible for severe acute respiratory syndrome, an airway disease that can be severe and fatal in a percentage of cases. Patients with severe COVID-19 can develop extrapulmonary lesions, with renal, hepatic, cardiac, neurological, and tissue involvement that can cause further severe complications. On December 21, 2021, the European Medicines Agency (EMA) authorized the marketing of the first COVID-19 vaccine. However, several randomized trials are ongoing to find effective, safe, and widely available treatments. The most severe stages of COVID-19 infection are characterized by a multi-system inflammatory state induced by a cytokine storm causing multi-organ injury. Epidemiologic evidence has shown that glucocorticoids (GCs), particularly dexamethasone, are used in severe, hospitalized patients with COVID-19 with good therapeutic benefit. COVID-19 can also damage the endothelial system, causing microcirculatory disturbances and consequently leading to functional organ disorders. The combination of endothelial dysfunction with a generalized inflammatory state may contribute to the general pro-coagulative state described in patients with COVID-19 with increased risk of venous and arterial occlusions. The aim of this article is to describe the therapeutic utility of GCs in stabilizing the vascular endothelial barrier in COVID-19 infection. Indeed, we believe that the stabilization of the endothelial barrier and the anti-inflammatory effect of GCs could be the main effect underlying the therapeutic efficacy in COVID-19 patients.
\end{abstract}

Keywords Desametasone $\cdot$ COVID-19 $\cdot$ SARS-CoV-2 $\cdot$ Pandemic $\cdot$ Inflammatory

\section{Introduction}

\section{Aim of this article}

The aim of this article is to describe the therapeutic utility of GCs in stabilizing the vascular endothelial barrier in COVID19 infection. The stabilization of the endothelial barrier and the anti-inflammatory effect of GCs could be the main effect underlying the therapeutic efficacy in COVID-19 patients.

Francesco Ferrara

francesco.ferrara@uslumbria1.it

Antonio Vitiello

antonio.vitiello2@uslumbria1.it

1 Usl Umbria 1, Pharmaceutical Department, A.Migliorati Street, 06132 Perugia, Italy

2 Usl Umbria 1, Pharmaceutical Department, Via XIV Settembre, 06132 Perugia, Italy

\section{The global pandemic COVID-19}

Since the beginning of the SARS-CoV-2 coronavirus outbreak in Wuhan China in November 2019, COVID-19 has rapidly spread around the world. In March 2020, the WHO declared a global pandemic status caused by COVID-19 (https://www.who.int/emergencies/diseases/novelcoronavirus-2019/situation-reports.)

\section{Covid-19, viral infection}

\section{Clinical manifestations}

SARS-CoV-2 virus is transmitted from human to human ( $\mathrm{Li}$ et al., 2020b). In most cases, the incubation period is approximately 5 days after exposure; in some cases, it can last up to 15 days. The infection in a good percentage of cases may have a totally asymptomatic or mildly symptomatic course. The most common symptoms are cough and dyspnea, myalgia and fatigue, and olfactory disturbances. Epidemiologic 
evidence shows that fever is present in approximately $90 \%$ of patients hospitalized with COVID-19. A percentage of COVID-19-positive patients presents gastrointestinal symptoms such as nausea and diarrhea (Chen et al. 2020). In a percentage of patients, SARS-CoV-2 infection can cause several serious complications: acute respiratory distress syndrome (ARDS) is the major complication in COVID-19positive patients. Bilateral interstitial pneumonia appears to be the most frequent severe manifestation of infection characterized by cough and dyspnea (Fu et al. 2020). However, in addition to the respiratory system, other organs, particularly the cardiovascular system, may also be affected. Epidemiological data report cases of acute cardiac injury from COVID-19. Thromboembolic complications, including pulmonary embolism, have also been reported. Some cases report hepatic injury (Struyf et al. 2020). Lesions of the lungs and other organs such as the heart or liver appear to be caused by direct or indirect damage from the virus (Chung et al. 2020). SARS-CoV-2 uses the entry receptor ACE- 2 to penetrate host cells ( $\mathrm{Li}$ et al. 2020a; Vitiello and Ferrara 2020a,b), the latter being expressed in several tissues, at the level of type II pneumocytes, cardiac cells, liver cholangiocytes, and endothelial cells. In the most severe stages of COVID-19 infection, a "cytokine cascade"(Vitiello et al. 2020a; Ferrara et al. 2020a) is generated, responsible for multi-system inflammation leading to organ injury (Ferrara et al. 2020b). As mentioned above, a percentage of COVID-19-infected patients show lesions of the cardiovascular system (Clerkin et al. 2020; Vitiello and Ferrara 2020c). Although the exact pathophysiological mechanism of cardiovascular injury in COVID19 remains to be elucidated, there are multiple possible causes, including acute ischemic injury due to coronary artery obstruction, inflammatory myocardial edema, endotheliitis, and tissue edema due to a dysregulated and systemic immune/ inflammatory response (Varga et al. 2020). Neurological damage is also associated with COVID-19 infection; binding of SARS-CoV-2 spike proteins to brain endothelial cells can result in loss of the blood-brain barrier, potentially causing the neurological symptoms associated with COVID-19. Evidence suggests that loss of vascular function and tissue edema play an important role in COVID-19 organ damage. First, there is invasion of endothelial cells (ECs) by the virus; second, there is generalized inflammation. The resulting endotheliitis is characterized by endothelial cell dysfunction. Endothelial dysfunction causes a systemic condition in which the endothelium loses its physiological and functional properties, such as vasodilation, fibrinolysis, and antiplatelet. This endothelium might explain the cardiovascular complications from COVID-19 (Teuwen et al. 2020). Furthermore, the decrease in ACE-2 in the more severe stages of infection leads to an increase in angiotensin 2 (Ang II) and activation of the kinin-kallikrein system (KKS) and increased vascular permeability. Endothelial dysfunction may be responsible for tissue edema and thrombosis formation (Fig. 1). The efficacy against inflammation and endothelial damage may be the main explanation for the efficacy of synthetic glucocorticoids (GCs) in patients with severe COVID-19. On December 21, 2021, the European Medicines Agency (EMA) granted marketing authorization for the first COVID-19 vaccine in people 16 years of age and older. To date, there are no direct antivirals against SARS-CoV-2, and therapeutic treatments are experimental (Who 2020; Vitiello et al. 2020a,b; Vitello and Ferrara 2021; Ferrara 2020).

\section{Normal endothelial function}

Endothelial tissue is the cell monolayer that lines the inner surface of blood vessels. In response to stimuli, the endothelium releases factors that regulate vasomotor function, inflammatory processes (e.g., neutrophil recruitment), angiogenesis, and hemostasis. Factors that modulate vascular tone (Daiber et al. 2017) are classified as endothelium-derived relaxation factors (EDRFs), including nitric oxide (NO), prostacyclin (PGI2), and endothelium-derived hyperpolarizing factor (EDHF), and endothelium-derived contraction factors (EDCFs), including angiotensin II, endothelin-1, and vasoconstrictor prostanoids. Impairment of NO synthesis in endothelial dysfunction is responsible for excess vasoconstriction with increased vessel tone as well as decreased antiaggregative activity.

\section{GCs and endothelites COVID-19 induced}

Synthetic GCs are glucocorticoid receptors (GCr) agonists and, to a lesser extent, mineralocorticoid receptors (MRs), both of which are members of the nuclear receptor superfamily of ligand-activated transcription factors (Alexander et al. 2008). The main GR responsible for the therapeutic effects of GCs is GR $\alpha$ (Walker 2007). In the vascular system, GRs are expressed by intact arteries, vascular smooth muscle cells, and endothelial cells. Therefore, the conditions suggest for direct modulation of endothelial function by GCs. Evidence from in vitro and ex vivo models suggests that GCs are capable of directly modulating endothelial function. However, their effects appear to differ depending on whether they are used in healthy or in inflammationassociated conditions. Epidemiological evidence has associated treatment with GCs, particularly dexamethasone, with good therapeutic efficacy in COVID-19 patients. In particular, recommendations on the use of GCs for COVID-19 patients are based largely on data from the RECOVERY trial, a large multi-center, randomized, open-label study. This study compared hospitalized patients who received up to 10 days of dexamethasone with those who received the standard of care. Mortality at 28 days was lower among patients who were treated with dexamethasone. This benefit was observed in patients who were mechanically ventilated or required supplemental oxygen at the time of 


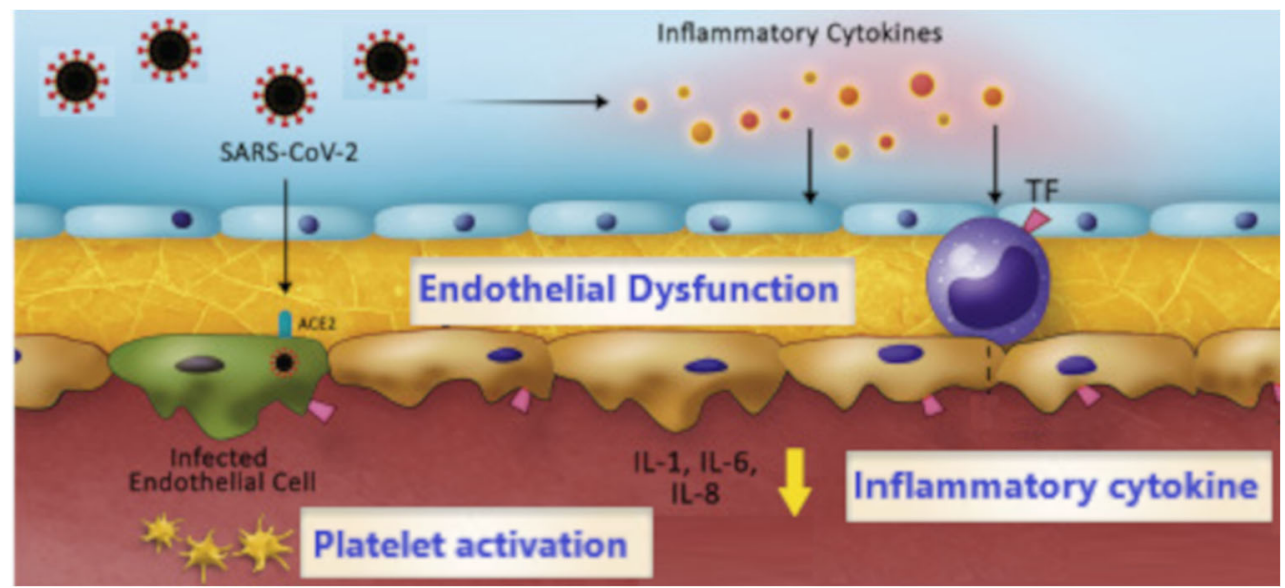

Fig. 1 The substances produced by the endothelium are vasoactive compounds, growth factors, mediators of inflammation, adhesion molecules, proteins of the hemostatic system. Through this wide range of compounds the endothelium intervenes in the control of vascular homeostasis, inflammation, immunity, hemostasis and performs a number of important metabolic functions The invasion of endothelial cells (EC) by the virus and the release of inflammatory cytokines cause inflammation of the endothelium. The resulting endotheliitis is characterized by endothelial cell dysfunction. Endothelial dysfunction causes a systemic condition in which the endothelium loses its physiological and functional properties, such as vasodilation, fibrinolysis, and antiplatelet. This induced endotheliitis may be responsible for tissue edema and the risk of thrombosis leading to organ damage in the COVID-19 patient

endothelial cell (EC) adhesion molecules, recruitment of inflammatory cells, cytokine release, and reduced nitric oxide (NO) bioactivity (Ait-Oufella et al. 2010; Lorant et al. 1995). Physiologically, endogenous glucocorticoids exert a permissive role in suppressing local and systemic inflammation. Administration of GCs, such as dexamethasone, is widely used to suppress inflammation, and indicated in autoimmune diseases, although the mechanisms by which they act are not fully understood (Lee and Burckart 1998; Longui 2007). The role of GCs on endothelial function under inflammatory conditions seems different than under physiological conditions. Compelling evidence supports a beneficial vascular effect of GCs in high-grade inflammation associated with septic shock, and this effect is mediated by activation of the endothelial GC receptor (Goodwin et al. 2013, 2014). The mechanisms involved in the beneficial effects of GCs on endothelial cells under inflammatory conditions are likely due to a decrease in endothelial expression of cytokines (IL-6, IL-8), G-CSF, VEGF, endothelin-1, NFkB, arginase 2, and COX-2. The use of GCs may lead to avoidance of microcirculatory disturbances, and consequently functional disturbances of all internal organs may also avoid endothelial dysfunction and generalized inflammatory state by indirectly reducing the general pro-coagulative state described in COVID-19 patients leading to venular and arteriolar occlusions. (Salvador et al. 2014; Lefer et al. 1980; Oakley and Cidlowski 2015).

\section{Conclusions}

Epidemiological evidence shows the efficacy of dexamethasone in severe COVID-19 in reducing mortality. We believe that the main anti-COVID-19 effect of GCs is associated, in 
parallel with known anti-inflammatory activities, with modulation of vascular and endothelial wall inflammation, reducing organ and tissue injury, edema formation, and the risk of arterial and venous occlusion, in the most severe stages of SARS-CoV-2 infection.

\section{Copyright}

The authors certify that the manuscript is original, never submitted to other journal for publication before. All authors contributed equally to the manuscript and had the opportunity to revise and approve the final text.

Authors' contribution Antonio Vitiello: Conceptualization, writingoriginal draft, methodology, writing-original draft.

Francesco Ferrara: Writing-review and editing, supervision, validation. The manuscript was written entirely by the authors. All authors made an equal contribution in the development of the paper.

\section{Compliance with ethical standards}

Conflict of interest The authors declare that they have no conflict of interest.

\section{References}

Ait-Oufella H, Maury E, Lehoux S, Guidet B, Offenstadt G (2010) The endothelium: physiological functions and role in microcirculatory failure during severe sepsis. Intensive Care Med 36(8):1286-1298

Alexander SP, Mathie A, Peters JA (2008) Guide to receptors and channels (GRAC), 3rd edition. Br J Pharmacol. 153 Suppl 2(Suppl 2): S1-209. doi: https://doi.org/10.1038/sj.bjp.0707746

Chen N, Zhou M, Dong X, Qu J, Gong F, Han Y, Qiu Y, Wang J, Liu Y, Wei Y, Xia J', Yu T, Zhang X, Zhang L (2020) Epidemiological and clinical characteristics of 99 cases of 2019 novel coronavirus pneumonia in Wuhan, China: a descriptive study. Lancet. 395(10223): 507-513. https://doi.org/10.1016/S0140-6736(20)30211-7

Chung TW, Sridhar S, Zhang AJ (2020) Olfactory dysfunction in coronavirus disease 2019 patients: observational cohort study and systematic review. Open Forum Infect Dis 7:ofaa199

Clerkin KJ, Fried JA, Raikhelkar J, Sayer G, Griffin JM, Masoumi A, Jain SS, Burkhoff D, Kumaraiah D, Rabbani LR, Schwartz A, Uriel N (2020) COVID-19 and cardiovascular disease. Circulation. 141(20): 1648-1655. https://doi.org/10.1161/CIRCULATIONAHA.120. 046941

Daiber A, Steven S, Weber A, Shuvaev VV, Muzykantov VR, Laher I, Li H, Lamas S, Münzel T (2017) Targeting vascular (endothelial) dysfunction. Br J Pharmacol 174(12):1591-1619. https://doi.org/10. 1111/bph.13517

Dorrance AM, Mack EA, Webb RC (2004) Glucocorticoids decrease GTP cyclohydrolase and tetrahydrobiopterin-dependent vasorelaxation through glucocorticoid receptors. J Cardiovasc Pharmacol 43: 8-13. https://doi.org/10.1097/00005344-200401000-00002

Ferrara F (2020) Antirheumatic in SARS-CoV-2: benefit or risk? Italian Journal of Medicine. 14(2):114-115. https://doi.org/10.4081/itjm. 2020.1290

Ferrara F, Granata G, Pelliccia C, La Porta R, Vitiello A (2020a) The added value of pirfenidone to fight inflammation and fibrotic state induced by SARS-CoV-2 : anti-inflammatory and anti-fibrotic therapy could solve the lung complications of the infection? Eur J Clin
Pharmacol 76(11):1615-1618. https://doi.org/10.1007/s00228-02002947-4

Ferrara F, Porta R, D'Aiuto V, Vitiello A (2020b) Remdesivir and COVID-19. Ir J Med Sci 17:1-2. https://doi.org/10.1007/s11845020-02401-5

Ferrara F, Porta R, Santilli P, D'Aiuto V, Vitiello A (2020c) Are multiple sclerosis therapies safe in severe acute respiratory syndrome coronavirus 2 times? Indian J Pharmacol 52(5):441-442. https://doi.org/ 10.4103/ijp.IJP_417_20

Fu L, Wang B, Yuan T, Chen X, Ao Y, Fitzpatrick T et al (2020) Clinical characteristics of coronavirus disease 2019 (COVID-19) in China: a systematic review and meta-analysis. J Infect 80(6):656-665. https://doi.org/10.1016/j.jinf.2020.03.041

Goodwin JE, Feng Y, Velazquez H, Sessa WC (2013) Endothelial glucocorticoid receptor is required for protection against sepsis. Proc Natl Acad Sci U S A 110:306-311. https://doi.org/10.1073/pnas. 1210200110

Goodwin JE, Feng Y, Velazquez H, Zhou H, Sessa WC (2014) Loss of the endothelial glucocorticoid receptor prevents the therapeutic protection afforded by dexamethasone after LPS. PLoS One 9:e108126. https://doi.org/10.1371/journal.pone.0108126

Horby P, Lim WS, Emberson JR, Mafham M, Bell JL, Linsell L et al. (2020) Dexamethasone in hospitalized patients with Covid-19 - preliminary report. N Engl J Med. NEJMoa2021436. doi: https://doi. org/10.1056/NEJMoa2021436

Lee JI, Burckart GJ (1998) Nuclear factor kappa B: important transcription factor and therapeutic target. J Clin Pharmacol 38(11):981-993

Lefer AM, Crossley K, Grigonis G, Lefer DJ (1980) Mechanism of the beneficial effect of dexamethasone on myocardial cell integrity in acure myocardial ischemia. Basic Res Cardiol 75(2):328-339. https://doi.org/10.1007/BF01907581

Li G, He X, Zhang L, Ran Q, Wang J, Xiong et al (2020a) Assessing ACE2 expression patterns in lung tissues in the pathogenesis of COVID-19. J Autoimmun 112:102463. https://doi.org/10.1016/j. jaut.2020.102463

Li Q, Guan X, Wu P, Wang X, Zhou L, Tong Y, Ren R, Leung KSM, Lau EHY, Wong JY, Xing X, Xiang N, Wu Y, Li C, Chen Q, Li D, Liu T, Zhao J, Liu M, Tu W, Chen C, Jin L, Yang R, Wang Q, Zhou S, Wang R, Liu H, Luo Y, Liu Y, Shao G, Li H, Tao Z, Yang Y, Deng Z, Liu B, Ma Z, Zhang Y, Shi G, Lam TTY, Wu JT, Gao GF, Cowling BJ, Yang B, Leung GM, Feng Z (2020b) Early transmission dynamics in Wuhan, China, of novel coronavirus-infected pneumonia. N Engl J Med 382(13):1199-1207. https://doi.org/10. 1056/NEJMoa2001316

Liu Y, Mladinov D, Pietrusz JL, Usa K, Liang M (2009) Glucocorticoid response elements and $11 \beta$-hydroxysteroid dehydrogenases in the regulation of endothelial nitric oxide synthase expression. Cardiovasc Res 81:140-147. https://doi.org/10.1093/cvr/cvn231

Longui CA (2007) Glucocorticoid therapy: minimizing side effects. J Pediatr 83(5 Suppl):S163-S177

Lorant DE, Zimmerman GA, McIntyre TM, Prescott SM (1995) Plateletactivating factor mediates procoagulant activity on the surface of endothelial cells by promoting leukocyte adhesion. Semin Cell Biol 6(5):295-303

Oakley RH, Cidlowski JA (2015) Glucocorticoid signaling in the heart: a cardiomyocyte perspective. J Steroid Biochem Mol Biol 153:27-34. https://doi.org/10.1016/j.jsbmb.2015.03.009

Ramzy D, Tumiati LC, Tepperman E, Sheshgiri R, Jackman J, Badiwala M, Rao V (2008) Dual immunosuppression enhances vasomotor injury: interactive effect between endothelin-1 and nitric oxide bioavailability. J Thorac Cardiovasc Surg 135:938-944. https://doi.org/ 10.1016/j.jtcvs.2007.09.075

Rogers KM, Bonar CA, Estrella JL, Yang S (2002) Inhibitory effect of glucocorticoid on coronary artery endothelial function. Am J Physiol Heart Circ Physiol 283:1922-1928. https://doi.org/10. 1152/ajpheart.00364.2002 
Salvador E, Shityakov S, Förster C (2014) Glucocorticoids and endothelial cell barrier function. Cell Tissue Res 355(3):597-605. https:// doi.org/10.1007/s00441-013-1762-z

Schäfer SC, Wallerath T, Closs EI, Schmidt C, Schwarz PM, Förstermann U, Lehr HA (2005) Dexamethasone suppresses eNOS and CAT-1 and induces oxidative stress in mouse resistance arterioles. Am J Physiol Heart Circ Physiol 288(1):H436-H444. https://doi.org/10.1152/ajpheart.00587.2004

Struyf T, Deeks JJ, Dinnes J, Takwoingi Y, Davenport C, Leeflang MM et al (2020) Cochrane COVID-19 Diagnostic Test Accuracy Group. Signs and symptoms to determine if a patient presenting in primary care or hospital outpatient settings has COVID-19 disease. Cochrane Database Syst Rev 7(7):CD013665. https://doi.org/10.1002/ 14651858

Teuwen LA, Geldhof V, Pasut A, Carmeliet P (2020) COVID-19: the vasculature unleashed. Nat Rev Immunol 20(7):389-391. https:// doi.org/10.1038/s41577-020-0343-0

Varga Z, Flammer AJ, Steiger P, Haberecker M, Andermatt R, Zinkernagel AS, Mehra MR, Schuepbach RA, Ruschitzka F, Moch H (2020) Endothelial cell infection and endotheliitis in COVID-19. Lancet. 395(10234):1417-1418. https://doi.org/10. 1016/S0140-6736(20)30937-5

Vitiello A, Ferrara F (2020a) Correlation between renin-angiotensin system and severe acute respiratory syndrome coronavirus 2 infection: what do we know? Eur J Pharmacol 883:173373. https://doi.org/10. 1016/j.ejphar.2020.173373
Vitiello A, Ferrara F (2020b) Pharmacological agents to therapeutic treatment of cardiac injury caused by Covid-19. Life Sci 262:118510. https://doi.org/10.1016/j.lfs.2020.118510

Vitiello A, Ferrara F (2020c) Remdesivir versus ritonavir/lopinavir in COVID-19 patients. Ir J Med Sci 18:1-2. https://doi.org/10.1007/ s11845-020-02440-y

Vitiello A, Ferrara F (2021) Therapeutic strategies for SARS-CoV-2 acting on ACE-2. Eur J Pharm Sci 156:105579. https://doi.org/10. 1016/j.ejps.2020.105579

Vitiello A, Ferrara F, Pelliccia C, Granata G, La Porta R (2020a) Cytokine storm and colchicine potential role in fighting SARS-CoV-2 pneumonia. Italian Journal of Medicine 14(2):88-94. https://doi.org/10. 4081/itjm.2020.124

Vitiello A, La Porta R, Ferrara F (2020b) Sacubitril, valsartan and SARSCoV-2. BMJ Evid Based Med. bmjebm-2020-111497. doi: https:// doi.org/10.1136/bmjebm-2020-111497

Walker BR (2007 Nov) Glucocorticoids and cardiovascular disease. Eur J Endocrinol 157(5):545-559. https://doi.org/10.1530/EJE-07-0455

World health organization (WHO) https://www.who.int/emergencies/ diseases/novel-coronavirus-2019/situation-reports. [Accessed 30 Nov 2020]

Publisher's note Springer Nature remains neutral with regard to jurisdictional claims in published maps and institutional affiliations. 